\title{
Vacuum insulation panels for thermal energy storage systems
}

\author{
Sankarshan Verma ${ }^{\star 1}$, Harjit Singh ${ }^{1}$ \\ ${ }^{1}$ Institute of Energy Futures, College of Engineering, Design and Physical Sciences, Brunel University \\ London, Uxbridge, UB8 3PH, UK \\ Email: harjit.singh@brunel.ac.uk
}

\begin{abstract}
The temperature of molten salts in the thermal energy storage tanks has strict bounds. A drop in temperature could cause local crystallization of the salt, while the maximum temperature is limited by the excess energy available through the concentrated solar power plant. In the present work, a system level (thermal energy storage tank) computer model has been developed to compare the effect of two different insulation materials i.e. an advanced Vacuum Insulation Panels (VIPs) and conventional glass wool under various scenarios of geometric features in the hot tank of an indirect thermal storage system. The heat storage temperature in our model is $393{ }^{\circ} \mathrm{C}$. Our full-length paper presents the results of this ongoing research, clearly detailing the simulation scenarios and exploring the viability of VIPs for insulating solar thermal storage tanks. A brief overview of VIP technology is also presented to benefit the solar energy end users and other stakeholders.
\end{abstract}

KEYWORDS: renewable energy, thermal energy storage, vacuum insulation panels

\section{INTRODUCTION}

The unavailability of solar irradiance during night or cloudy days has made the link between concentrated solar power (CSP) plants and thermal energy storage (TES) inextricable. Although TES technology at plants such as Andasol 3 (Spain), Diwakar (India) and Aurora Solar Energy Project (Australia) have been installed as a proof of concept, yet most of the CSP plants including Ivanpah Solar Electric Generating System (USA) and Waad AI Shamal ISCC Plant (Saudi Arabia) donot have a TES option [1]. One of the major reasons lie in the complexity invovled in storage.

The thermal energy can either be stored, as sensible heat, in the heat transfer fluid itself (direct storage) or in a different medium (in-direct storage), such as a molten salt, in two separate tanks: cold tank and hot tank. The molten salt from cold tanks is passed through a heat exchanger to the hot tank when solar irradiance is at its peak, thereby storing the excess thermal energy. While the iradiance is not strong enough, the salt is discharged from the hot tank and passed through the heat exchanger to extract the thermal energy which can be used to run the turbine. The most common molten salt used for this application, $60 \% \mathrm{NaNO}_{3}$ and $40 \%$ $\mathrm{KNO}_{3}$, has a high freezing point $\left(220^{\circ} \mathrm{C}\right)$. This means that a drop in temperature of the salt at any point below $220^{\circ} \mathrm{C}$ could cause crystallization of the salt, which could cause collapse of the entire plant [2]. Furthermore, the salt in hot tank must remain at a minimum specified temperature (around $393^{\circ} \mathrm{C}$ for Andasol) so that enough heat can be extracted to run the turbine. At the same time, there is an upper limit on maximum temperature that the salt could have based on excess thermal energy available from the CSP plant. Thus, there is a clear ground to develop techniques to minimise heat losses from the TES tanks to maintain the temperature of the salt in both hot and cold TES tanks.

As Fourier law suggests, the rate of heat loss can be reduced by either increasing the thickness of insulation on the tank or by using an insulation with low thermal conductivity. Presently, due to high temperatures involved, thick layers of mineral wool or glass wool are used to insulate the TES tanks. Vacuum insulation panels (VIPs), which are increasingly being used in cold chain equipments like refrigerators, cold storage boxes etc. $[3,4]$ could also be effective to suppress the heat losses from TES tanks, due to their extremely low thermal conductivity $\left(0.004 \mathrm{~W} \mathrm{~m}^{-1} \mathrm{~K}^{-1}\right.$ at room temperature) [5]. In the present work, we developed a computer model to compute the rate of heat loss from a hot TES tank throughout the day, with varying ambient temperature, including its charging and discharging processes. The rate of heat loss from walls, top and bottom of the tank was separately calculated. The total rate of heat loss, which was the sum of these individual losses, was compared for various thicknesses of two types of insulation i.e. glass wool and VIPs. Also, based on extinction coefficients and $p_{1 / 2}$ values, a suitable VIP core material was chosen from literature and its thermal conductivity as a function of temperature was calculated.

\section{MODEL}


A fully parametric model of a cylindrical hot tank was developed in COMSOL Multiphysics 5.5 (see figure 1). The diameter and the height were set to $36 \mathrm{~m}$ and $14 \mathrm{~m}$ respectively, as in the case of Andasol 1 [1]. The body of tank was made of $5 \mathrm{~mm}$ thick steel. The storage temperature in the hot tank was set at constant value of $393^{\circ} \mathrm{C}$. Taking advantage of the tank's geometry, the model was set as a 2D axis-symmetric geometry. The mesh in the tank's body and insulation was set as free triangular with element sizes ranging from $1.8 \mathrm{~m}$ to $0.008 \mathrm{~m}$. The mesh for regions inside tank and the ground, was mapped accordingly. In total, the model consisted of around 89727 domain elements and 7381 boundary elements.

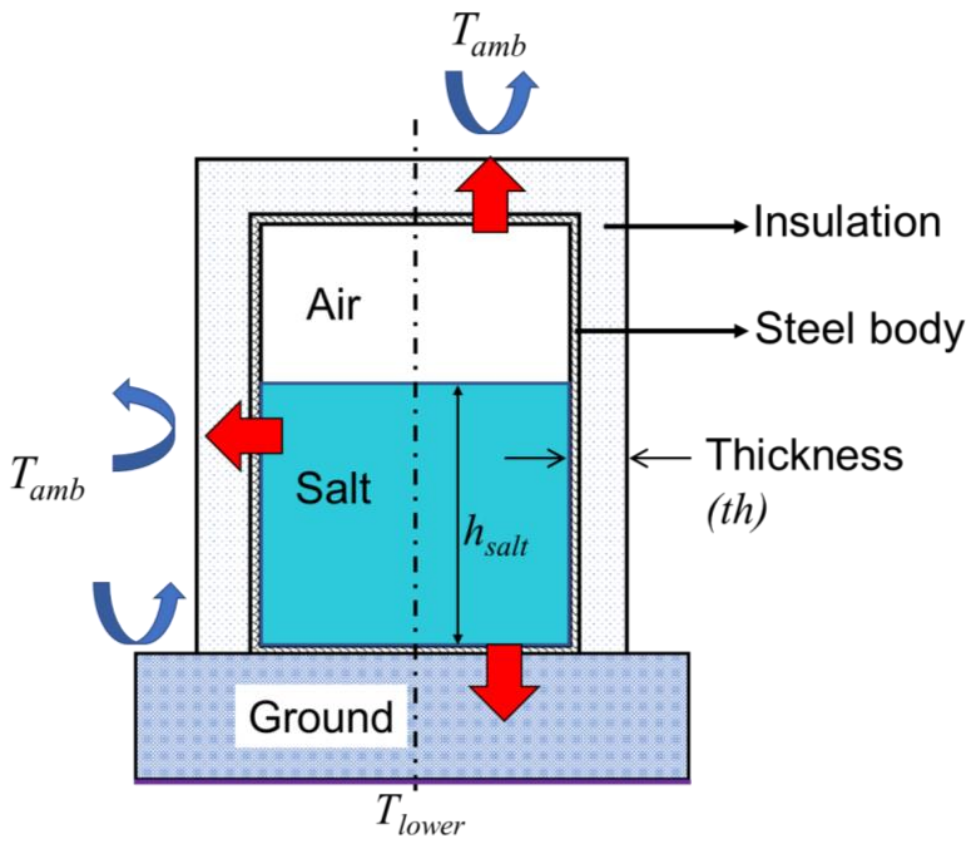

Figure 1 2D schematic of the thermal storage tank. The red arrows represent the heat transferred due to conduction and radiation and the curved arrows represent convective heat transfer.

\subsection{Boundary conditions}

The storage tank loses heat through all three modes i.e. conduction, convection and radiation. The heat escapes through walls and top lid to ambient atmosphere via natural convection and to the ground via conduction. The base of the tank is set as $1 \mathrm{~m}$ concrete, with a constant temperature of $25^{\circ} \mathrm{C}$ at its bottom. The ambient temperature, which plays a significant role in convective heat transfer, was taken from a weather station located in Riyad, Saudi Arabia recorded on June 21, 2019 [6]. The profile of ambient temperature was slightly modified to make our model computationally less expensive (figure 2).

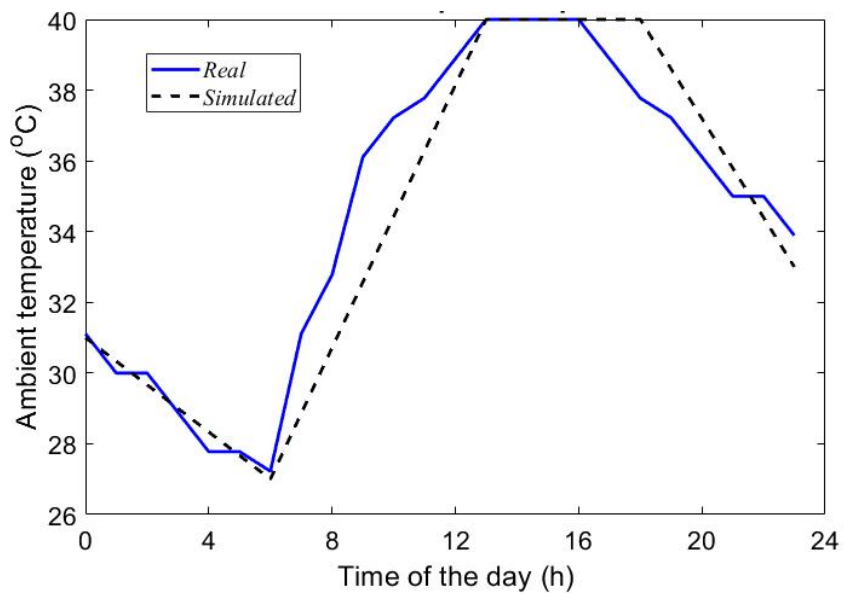

Figure 2 Ambient temperature profile input to the model. 'Real' denotes the actual temperature profile and 'Simulated' denotes the one used as input in our model.

In this model, it was assumed that the peak hours in which the charging of hot tank occurs are from 11:00 to 15:00. During this time, the height of salt, which significantly affects heat flow rate through the tank, keeps increasing. After 15:00, when tank was fully filled, the salt stayed in the tank till sun's irradiation was strong enough to generate power i.e. 17:00, after which the hot tank began discharging the salt and the height of salt 
started falling. At any stage, it was assumed that the salt's temperature in the tank was $393^{\circ} \mathrm{C}$, as this was a non-negotiable aspect for smooth functioning of the power plant. In our model, instead of considering a continuous rise or fall of height of the salt in the tank during charging and discharging, it was assumed that it occurs in steps of one hour, to make the model computationally less expensive (figure 3 ).

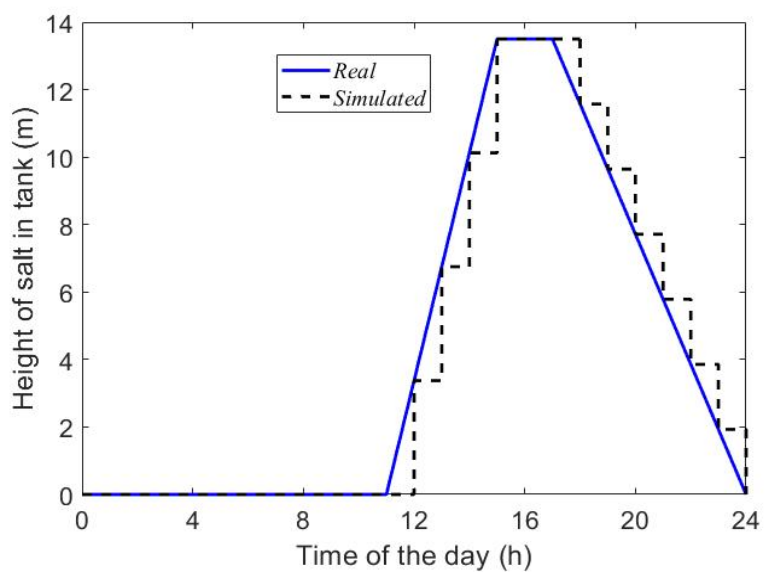

Figure 3 Height of salt in the hot tank with time of the day.

The model was run for two types of insulation materials i.e. glass wool and vacuum insulation panels each with varying thickness. The model computes rate of heat loss for a full day at regular intervals, including filling and unfilling processes. A brief introduction to vacuum insulation panels and the heat transfer phenomenon through them is presented in section 1.2.

\subsection{Vacuum Insulation Panels}

Vacuum insulation panels, or VIPs, are insulations which have the ability to provide a thermal conductivity value of $4 \mathrm{mWm}^{-1} \mathrm{~K}^{-1}$ at room temperatures, which is around 10 times lower than glass wool's thermal conductivity. VIPs consist of a porous core material made of powder / fibers / foam which is evacuated to pressures ranging from $1 \mathrm{mbar}$ to $0.1 \mathrm{mbar}$ and sealed in a polymer / metal based envelope [3,4].

Generally, the heat transfer through VIPs is considered to be occuring parallely, through gaseous conduction in pores, solid conduction through core's matrix and radiation and thus the total thermal conductivity is a sum of the three conductivities (equation 1).

$$
k_{\text {total }}=k_{s}+k_{g}+k_{r}
$$

The evacuation at low pressure leads to supression of gaseous conductivity $\left(k_{g}\right)$ and convection in the core material and highly porous nature of the core leads to low solid conductivity $\left(k_{s}\right)$. This is the reason behind extremely low overall thermal conductivity offered by VIP. Various opacifying substances like silicon carbide and iron oxide are added in the core material to supress the heat transfer through radiation, or radiative conductivity $\left(k_{r}\right)$, which becomes a dominant mode at high temperatures.

As an input to our model, we chose a VIP sealed at 1 mbar with core made of $80 \%$ precipitated silica and $20 \%$ $\mathrm{SiC}$. The temperature dependent thermal conductivity of this VIP was calculated using data from literature [7] and equations 1-3 (see figure 4).

$$
\begin{aligned}
k_{r}(T) & =\frac{16 n^{2} \sigma T^{3}}{3 \rho e} \\
k_{g}(T) & =\frac{k_{g}^{0}(T)}{1+p^{p_{1 / 2} / p}}
\end{aligned}
$$


where $n$ is the refractive index of core material which can be considered 1 because of its highly porous nature, $\sigma$ the Stefan-Boltzman constant, $T$ the mean operating temperature of the VIP, $\rho$ the density of core material, $e$ the specific extinction coefficient, $k_{g}^{0}$ the thermal conductivity of free air, $p_{1 / 2}$ a material specific constant and $p$ the pressure of air inside VIP.

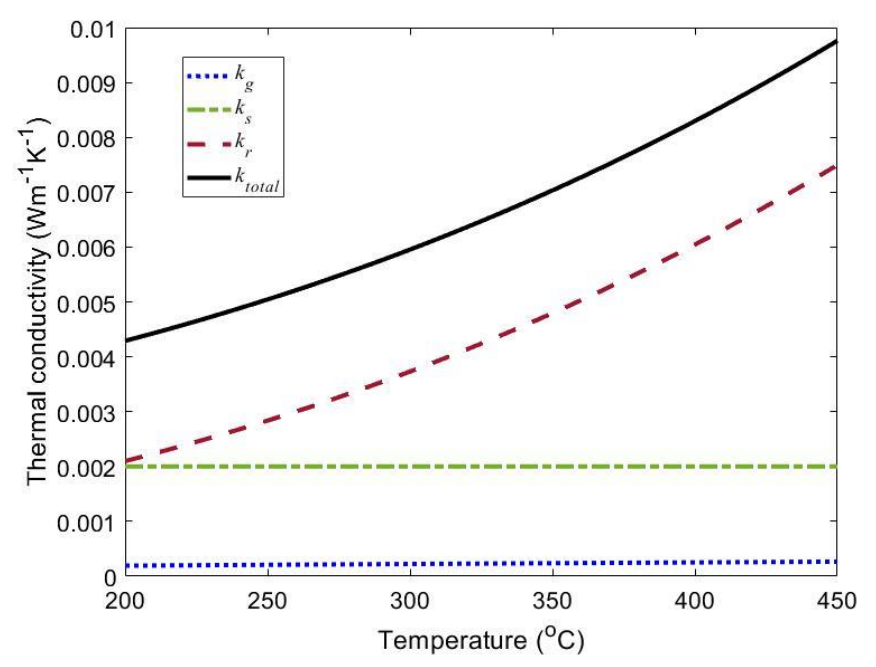

Figure 4 Total thermal conductivity of the VIP and its constituents as a function of temperature.

In contrast, the thermal conductivity of glass wool is around 10 times higher and is given by the equation 4 .

$$
k_{\text {glass wool }}=\frac{0.0318-0.0283}{30} \max (0, T-263.15)+0.0283
$$

\section{RESULTS AND DISCUSSIONS}

The rate of heat loss was calculated for various thicknesses of glass wool and the VIP. The results are as shown below (figure 5, 6).

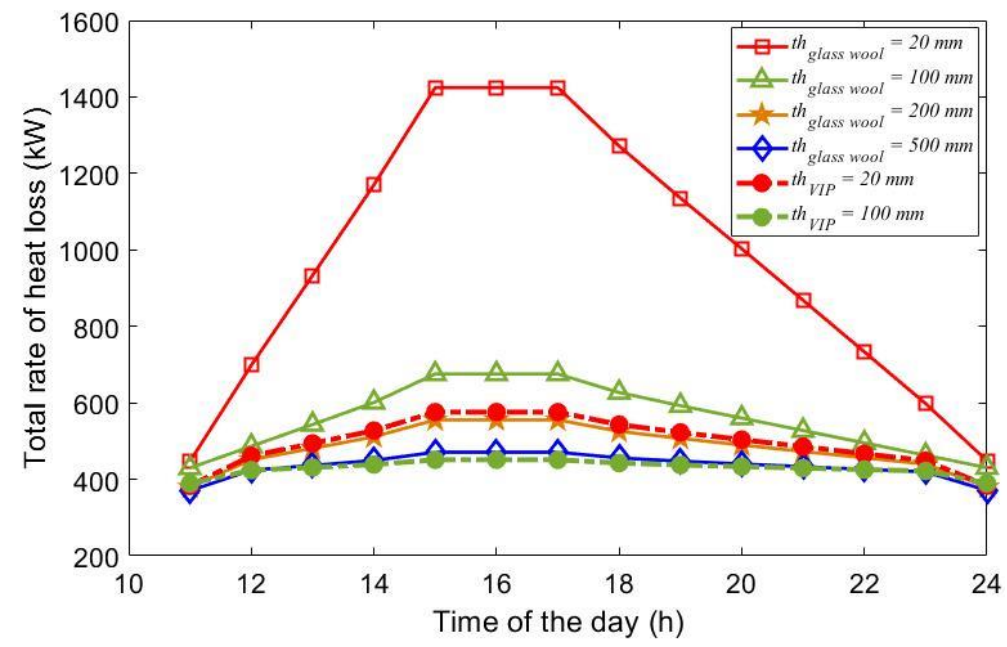

Figure 5 Total rate of heat loss through the tank with varying insulation thicknesses of glass wool (solid) and VIP (dashed).

The results clearly indicate how using VIPs can benefit the tank. The total rate of heat loss reached a peak of $1400 \mathrm{~kW}$ when the tank was insulated with $20 \mathrm{~mm}$ thick glass wool which could be suppressed to a around $420 \mathrm{~kW}$ by increasing the insulation thickness to $500 \mathrm{~mm}$. On the other hand, a $100 \mathrm{~mm}$ thick VIP is comparable in performance, with $500 \mathrm{~mm}$ thick glass wool thus saving $5 \%$ of the tank's volume, which could be used to store more salt and thus more power. This is due to extremely low thermal conductivity of the VIP. 
One notable characteristic of all heat loss graphs is the peak in the middle region. This peak occurs when the tank is fully filled with the salt and thus the heat loss through walls and top increase. As discussed earlier, the total rate of heat loss is a sum of that from top, bottom and the walls (figure 6). It is interesting to note that with a tank insulated with glass wool, the major loss occured through the walls whereas for a VIP insulated tank, the major loss occured through the bottom or the base. A solution to this could be to insulate the floor with VIPs as well.
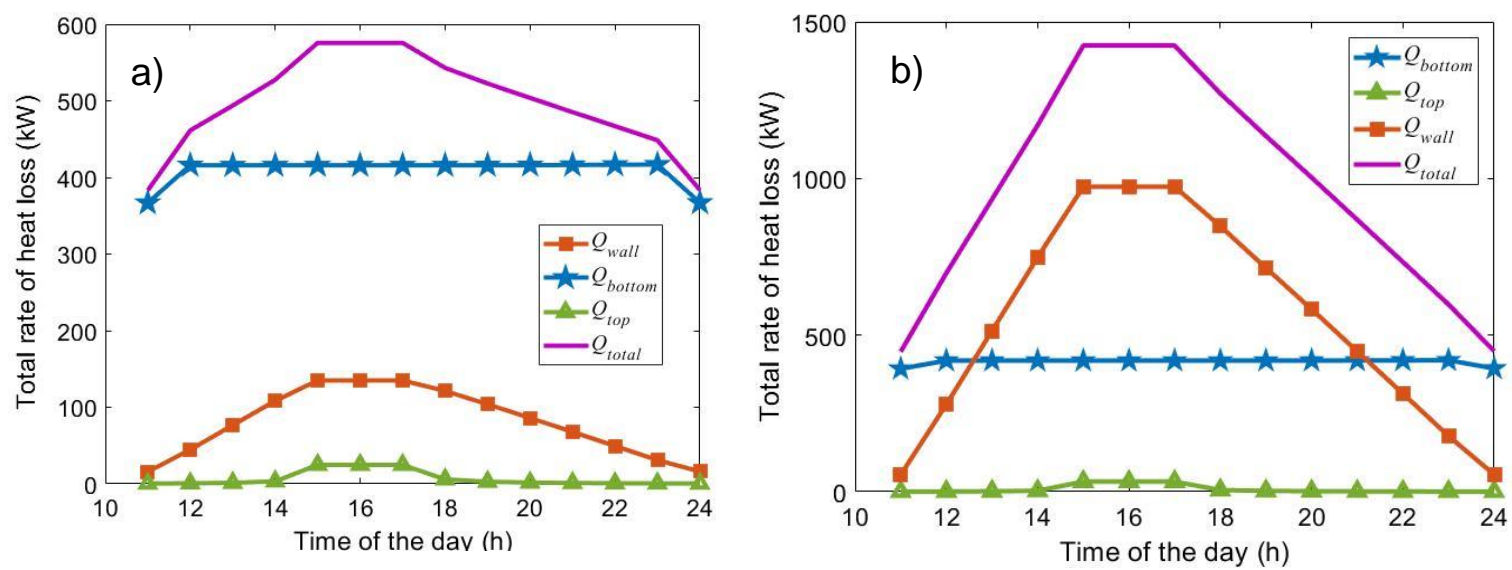

Figure 6 Total rate of heat loss and its constituents for a hot tank insulated with $20 \mathrm{~mm}$ thick a) VIP and b) glass wool.

\section{CONCLUSION}

A heat transfer model of a thermal storage tank containing the hot salt at $393^{\circ} \mathrm{C}$ was developed. The rate of heat loss was calculated throughout the day which included the charging and discharging process for two types of insulation materials i.e. glass wool, which is conventially used to insulate the tanks and a suitable VIP, which offered a thermal conductivity of around $8.5 \mathrm{mWm}^{-1} \mathrm{~K}^{-1}$ at $400{ }^{\circ} \mathrm{C}$. The thickness of these materials was varied and the total rate of heat loss calculated at every step. It was found that a 100 $\mathrm{mm}$ thick VIP could be as efficient as $500 \mathrm{~mm}$ thick conventional glass wool insulation throught the day. Also, it was found out that, the major heat loss in a VIP insulated tank occurred through the base of the tank.

\section{REFERENCES}

[1] NREL, Concentrating Solar Power Projects, (n.d.). https://solarpaces.nrel.gov/ (accessed July 15, 2020).

[2] C. Suárez, A. Iranzo, F.J. Pino, J. Guerra, Transient analysis of the cooling process of molten salt thermal storage tanks due to standby heat loss, Applied Energy. 142 (2015) 5665. https://doi.org/10.1016/j.apenergy.2014.12.082.

[3] M. Alam, H. Singh, M.C. Limbachiya, Vacuum insulation panels (vips) for building construction industry - a review of the contemporary developments and future directions, Applied Energy. 88 (2011) 3592-3602. https://doi.org/10.1016/j.apenergy.2011.04.040.

[4] S. Verma, H. Singh, Vacuum insulation panels for refrigerators, International Journal of Refrigeration. 112 (2020) 215-228. https://doi.org/10.1016/j.ijrefrig.2019.12.007.

[5] S. Fantucci, A. Lorenzati, G. Kazas, D. Levchenko, G. Serale, Thermal energy storage with super insulating materials: A parametrical analysis, Energy Procedia. 78 (2015) 441-446. https://doi.org/10.1016/j.egypro.2015.11.691.

[6] TWC Product and Technology LLC, Riyadh, Riyadh, Saudi Arabia Weather History, (2020). https://www.wunderground.com/history/daily/sa/riyadh/OERK.

[7] R. Caps, J. Fricke, Thermal conductivity of opacified powder filler materials for vacuum insulations, International Journal of Thermophysics. 21 (2000) 445-452.

https://doi.org/10.1023/A:1006691731253. 